\title{
The T2-FLAIR Mismatch Sign as an Imaging Indicator of IDH-Mutant, 1p/19q Non-Codeleted Lower Grade Gliomas: A Systematic Review and Diagnostic Accuracy Meta-Analysis
}

\author{
Antonis Adamou ${ }^{1}$ (D), Eleftherios T. Beltsios ${ }^{2}$ and Panagiotis Papanagiotou ${ }^{3,4, *(D)}$ \\ 1 Department of Radiology and Medical Imaging, University of Thessaly, 41110 Larissa, Greece; \\ antonadamou@gmail.com \\ 2 Faculty of Medicine, School of Health Sciences, University of Thessaly, 41110 Larissa, Greece; \\ beltsioseleftherios@gmail.com \\ 3 Department of Diagnostic and Interventional Neuroradiology, Hospital Bremen-Mitte/Bremen-Ost, \\ 28205 Bremen, Germany \\ 4 First Department of Radiology, School of Medicine, National \& Kapodistrian University of Athens, \\ Areteion Hospital, 11528 Athens, Greece \\ * Correspondence: papanagiotou@me.com
}

\section{check for}

updates

Citation: Adamou, A.; Beltsios, E.T.; Papanagiotou, P. The T2-FLAIR Mismatch Sign as an Imaging Indicator of IDH-Mutant, 1p/19q Non-Codeleted Lower Grade Gliomas: A Systematic Review and Diagnostic Accuracy Meta-Analysis. Diagnostics 2021, 11, 1620. https://doi.org/10.3390/ diagnostics 11091620

Academic Editor: Alessio Imperiale

Received: 17 June 2021

Accepted: 31 August 2021

Published: 4 September 2021

Publisher's Note: MDPI stays neutral with regard to jurisdictional claims in published maps and institutional affiliations.

Copyright: (c) 2021 by the authors. Licensee MDPI, Basel, Switzerland. This article is an open access article distributed under the terms and conditions of the Creative Commons Attribution (CC BY) license (https:/ / creativecommons.org/licenses/by/ $4.0 /)$.
Abstract: The study's objective was the evaluation of the diagnostic accuracy of the T2-FLAIR mismatch sign in terms of diagnosing IDH-mutant non-codeleted (IDHmut-Noncodel) lower grade gliomas (LGG) of the brain. We searched the MEDLINE, Scopus and Cochrane Central databases. The last database search was performed on 12 April 2021. Studies that met the following were included: MRI scan assessing the presence of T2-FLAIR mismatch sign, and available IDH mutation and $1 p / 19 q$ codeletion status. The quality of studies was assessed using the QUADAS- 2 tool. Twelve studies involving 14 cohorts were included in the quantitative analysis. The diagnostic odds ratio [DOR (95\% confidence interval; CI)] was estimated at $34.42(20.95,56.56), P_{z}<0.01$. Pooled sensitivity and specificity $(95 \% \mathrm{CI})$ were estimated at $40 \%\left(31-50 \% ; P_{z}=0.05\right)$ and $97 \%\left(93-99 \% ; P_{z}<0.01\right)$, respectively. The likelihood ratio $(\mathrm{LR} ; 95 \% \mathrm{CI})$ for a positive test was $11.39\left(6.10,21.29 ; P_{z}<0.01\right)$ and the $\operatorname{LR}(95 \% \mathrm{CI})$ for a negative test was $0.40\left(0.24,0.65 ; P_{z}<0.01\right)$. The T2-FLAIR mismatch sign is a highly specific biomarker for the diagnosis of IDHmut-Noncodel LGGs. However, the test was found positive in some other tumors and had a high number of false negative results. The diagnostic accuracy of the mismatch sign might be improved when combined with further imaging parameters.

Keywords: T2-FLAIR mismatch sign; glioma; astrocytoma; diagnostic accuracy; systematic review; meta-analysis

\section{Introduction}

Diagnosing and treating malignant brain tumors is challenging for clinicians. Histopathology remains the gold standard for the diagnosis of such tumors. The molecular differentiation of brain tumors has become a useful guiding tool for clinicians. In 2016, WHO published the revised classification of tumors of the central nervous system (CNS), which includes the molecular profile of each tumor subtype [1].

Radiomic features are radiological parameters that may contribute in accurately diagnosing a disease, by extracting and quantifying information from medical images. Following the trend for digitalization of the information in clinical practice, radiomics represented a useful tool to support clinicians in decision-making [2]. Several radiomic features have been tested, in an attempt to differentiate between gliomas of the brain. Among them, the T2-FLAIR mismatch sign is a radiomic feature reported by multiple studies as a highly specific biomarker of diffuse astrocytomas (IDH-mutant non-codeleted lower grade gliomas; IDHmut-Noncodel LGGs) of the brain. This feature is defined by a mismatch in T2 and 
FLAIR magnetic resonance (MR) sequences, particularly the presence of complete/nearcomplete hyperintense signal on T2WI, and relatively hypointense signal on FLAIR except for a hyperintense peripheral rim [3].

Given the importance of the mismatch sign potentially implicating the non-invasive diagnosis of IDHmut-Noncodel LGGs, the present study is intended at evaluating the diagnostic accuracy of the T2-FLAIR mismatch sign in terms of diagnosing these tumors.

\section{Materials and Methods}

\subsection{Protocol}

The protocol for this systematic review and meta-analysis was registered to the PROSPERO registry for systematic review protocols (ID number: CRD42021248328) and is available in full on https:/ / www.crd.york.ac.uk/prospero/display_record.php?ID=CRD4 2021248328 (retrieved 15 May 2021).

\subsection{Literature Search}

A comprehensive search of the MEDLINE, Scopus and Cochrane Central databases was conducted. The last database search was performed on 12 April 2021. The search algorithm included the following keywords combined with "AND" and "OR" Boolean operators: "radiomic features", "T2-FLAIR", "mismatch sign", "glioma". The references of each article were manually screened for eligible articles. Furthermore, the related articles section in each database was reviewed for eligible articles.

\subsection{Inclusion and Exclusion Criteria}

Studies that met both the inclusion criteria were included: (1) MRI scan assessing the presence of T2-FLAIR-mismatch sign, (2) available IDH mutation and 1p/19q codeletion status. Exclusion criteria were (1) did not include the radiomic feature of interest, (2) reviews/case reports/letters, (3) no English language, and (4) 1p/19q codeletion status not reported.

\subsection{Data Extraction}

Two authors (A.A. and E.T.B.) reviewed the titles and abstracts for eligibility. Discrepancies between reviewers were resolved by a third reviewer (P.P.). The full-text articles of the selected studies were further evaluated. Only studies that met the inclusion criteria were eventually included. Data were collected for the following variables: (1) study characteristics (author, year of publication, number of cases, median age, M/F ratio, WHO grades, and interrater agreement), (2) number of patients with T2-FLAIR mismatch sign (positive or negative), (3) IDH mutation and $1 \mathrm{p} / 19 \mathrm{q}$ codeletion status.

\subsection{Statistical Analysis}

We used the hierarchical regression approach (hierarchical summary receiver operating characteristic, HSROC) to analyze the diagnostic data of each study [4]. The pooled diagnostic odds ratio (DOR) and its 95\% confidence interval (95\% CI) were used to determine the diagnostic effectiveness of the mismatch sign.

We calculated the heterogeneity of the studies using the Cochran's $Q$ and $I^{2}$ indices. The random effects model was applied when heterogeneity was $I^{2}>75 \%$ and/or $P_{Q}<0.10$. Otherwise, the fixed effects model was applied. Additionally, pooled sensitivity and specificity and their $95 \%$ CI were calculated. The diagnostic parameters of positive predictive value (PPV), negative predictive value (NPV), likelihood ratio for a positive test (LR+), and likelihood ratio for a negative test (LR-) were also calculated.

The statistical analysis was performed with the OpenMeta[Analyst] for OS X Sierra (10.12) software [5]. Finally, the PRISMA-DTA guidelines for reporting reviews and metaanalyses of diagnostic test accuracy studies were also applied (Table S1; Supplementary Material) [6]. 


\subsection{Critical Appraisal and Risk of Bias Assessment}

The Quality Assessment of Diagnostic Accuracy Studies (QUADAS-2) tool [7] was used to assess risk of bias for each study. The QUADAS-2 tool is publicly available at www.quadas.org (retrieved 30 May 2021).

\section{Results}

\subsection{Search Results and Characteristics of the Included Studies}

The structured search of the databases and the manual screen of the references and related articles section retrieved 392 studies published between 2016 and 2021. Duplicates were removed and titles and abstracts were reviewed for their eligibility, resulting in 14 potentially eligible studies. The full-text article of each study was further reviewed. Two studies were excluded, both because they did not provide the $1 p / 19 q$ codeletion status of the patients' gliomas. Twelve studies were eventually included in the quantitative analysis, involving 1736 patients with WHO Grade II or III gliomas of the brain. Only two of the studies included cases with WHO Grade IV gliomas. In these studies, we only included the WHO Grade II and III cases in our quantitative analysis. The age of the subjects included in the present study ranged from 18 to 86 years old. The study selection flowchart according to the PRISMA guidelines is shown in Figure 1. The main characteristics of the included studies are presented in Table 1.

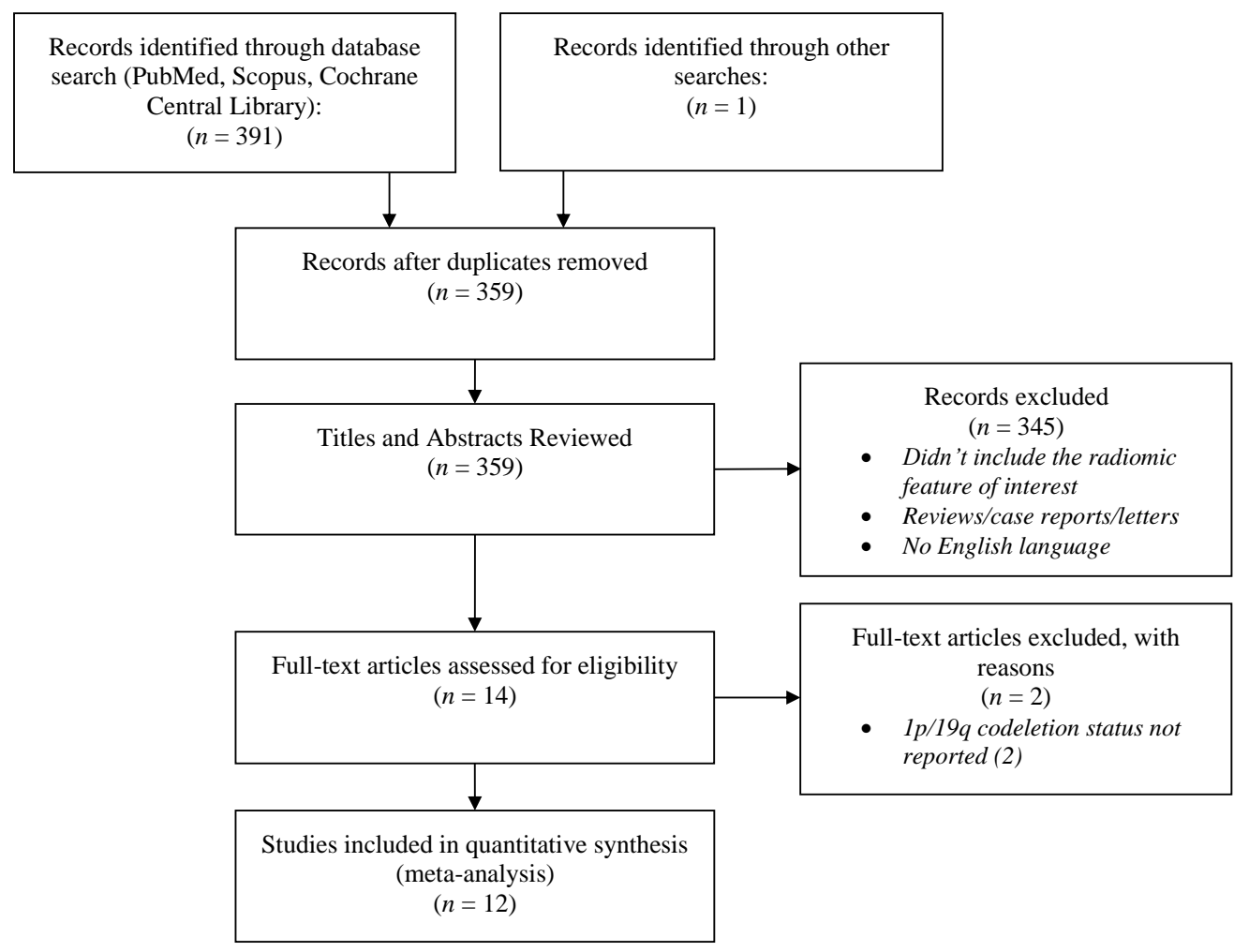

Figure 1. The PRISMA flow diagram of the study selection process.

\subsection{Diagnostic Test Performance for IDHmut-Noncodel Gliomas}

Due to low heterogeneity $\left(I^{2}=\mathrm{NA}, p=0.22\right)$, a fixed effects model (Mantel-Haenszel test) was applied to identify the diagnostic performance of the T2-FLAIR mismatch sign. The pooled quantitative analysis revealed a statistically significant linkage between the T2-FLAIR mismatch sign and the diagnosis of IDHmut-Noncodel LGGs [DOR (95\% CI): $\left.34.42(20.95,56.56) ; P_{z}<0.01\right]$. The forest plot for the pooled DOR is shown in Figure 2. 
Table 1. Baseline characteristics of the included studies.

\begin{tabular}{|c|c|c|c|c|c|c|c|}
\hline Study-YOP & $n$ & Mean Age & M/F Ratio & $\begin{array}{c}\text { WHO } \\
\text { Grade II }\end{array}$ & $\begin{array}{c}\text { WHO } \\
\text { Grade III }\end{array}$ & $\begin{array}{l}\text { Interobserver } \\
\text { Agreement }\end{array}$ & $\begin{array}{l}\text { Method of Mismatch } \\
\text { Identification }\end{array}$ \\
\hline $\begin{array}{c}\text { Patel SH } \\
\text { et al.2017 [3] }\end{array}$ & 125 & $\begin{array}{c}45.5 \\
(20-75)\end{array}$ & $62 / 63$ & 58 & 67 & 0.73 & $\begin{array}{l}\text { Two neuroradiologists, both } \\
\text { blinded to the molecular status. }\end{array}$ \\
\hline $\begin{array}{c}\text { Patel SH } \\
\text { et al.2017 [3] }\end{array}$ & 82 & $\begin{array}{c}45 \\
(21-82)\end{array}$ & $44 / 38$ & 35 & 47 & 0.73 & $\begin{array}{l}\text { Two neuroradiologists, both } \\
\text { blinded to the molecular status. }\end{array}$ \\
\hline $\begin{array}{l}\text { Lasocki A } \\
\text { et al.2018 [8] }\end{array}$ & 59 & na & na & 43 & 16 & 0.88 & $\begin{array}{l}\text { Two neuroradiologists both } \\
\text { blinded to the molecular status. }\end{array}$ \\
\hline $\begin{array}{l}\text { Broen MPG } \\
\text { et al.2018 [9] }\end{array}$ & 154 & $\begin{array}{c}43 \\
(20-82)\end{array}$ & $86 / 68$ & 133 & 9 & 0.75 & $\begin{array}{l}\text { One neurologist and a } \\
\text { neuroradiologist, both blinded to } \\
\text { the molecular status. }\end{array}$ \\
\hline $\begin{array}{c}\text { Juratli TA } \\
\text { et al.2018 [10] }\end{array}$ & 133 & $\begin{array}{c}40 \\
(18-86)\end{array}$ & na & 57 & 67 & 0.86 & $\begin{array}{l}\text { One neuroradiologist and a } \\
\text { neurosurgeon, both blinded to the } \\
\text { molecular status. A third } \\
\text { reviewer assessed any } \\
\text { disagreement. }\end{array}$ \\
\hline $\begin{array}{l}\text { Batchala PP } \\
\text { et al.2019 [11] }\end{array}$ & 102 & $\begin{array}{c}41 \\
(20-75)\end{array}$ & $50 / 52$ & 59 & 43 & 0.56 & $\begin{array}{l}\text { Two neuroradiologists, both } \\
\text { blinded to the molecular status. }\end{array}$ \\
\hline $\begin{array}{c}\text { Lee MK } \\
\text { et al.2019 [12] }\end{array}$ & 110 & 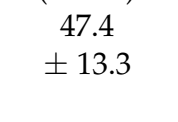 & $56 / 54$ & 45 & 65 & ICC 89 & $\begin{array}{l}\text { Two neuroradiologists, both } \\
\text { blinded to the molecular status. } \\
\text { Two neurosurgeons. A }\end{array}$ \\
\hline $\begin{array}{c}\text { Corell A } \\
\text { et al.2020 } \perp \\
{[13]}\end{array}$ & 135 & $\begin{array}{c}\text { pr: } 45 \\
\pm 14.3 \text { retr: } \\
47.9 \pm 15.7\end{array}$ & $84 / 56$ & na & na & 0.77 & $\begin{array}{l}\text { neuroradiologist resolved any } \\
\text { disagreement. A senior } \\
\text { neuroradiologist resolved further } \\
\text { disagreement. }\end{array}$ \\
\hline $\begin{array}{c}\text { Deguchi S } \\
\text { et al.2020 [14] }\end{array}$ & 64 & $\begin{array}{c}39 \\
(20-65)\end{array}$ & $14 / 8$ & 38 & 26 & 0.73 & $\begin{array}{c}\text { Two neurosurgeons, both blinded } \\
\text { to each other's results. A } \\
\text { radiologist confirmed their } \\
\text { findings. }\end{array}$ \\
\hline $\begin{array}{c}\text { Foltyn M } \\
\text { et al.2020 } \perp \\
{[15]}\end{array}$ & 408 & $\begin{array}{c}57 \\
(47-69)\end{array}$ & $228 / 180$ & 61 & 52 & 0.75 & $\begin{array}{l}\text { Two radiology residents and one } \\
\text { radiologist, all blinded to the } \\
\text { molecular status. }\end{array}$ \\
\hline $\begin{array}{l}\text { Aliotta E } \\
\text { et al.2020 [16] }\end{array}$ & 134 & na & na & na & na & na & $\begin{array}{l}\text { One neuroradiologist, both } \\
\text { blinded to the molecular status. }\end{array}$ \\
\hline $\begin{array}{c}\text { Aliotta E } \\
\text { et al.2020 [16] }\end{array}$ & 93 & na & na & na & na & na & $\begin{array}{c}\text { One neuroradiologist, blinded to } \\
\text { the molecular status. }\end{array}$ \\
\hline $\begin{array}{c}\text { Yang X } \\
\text { et al.2020 [17] }\end{array}$ & 142 & $\begin{array}{l}39.74 \\
\pm 10.09\end{array}$ & $43 / 26$ & na & na & na & $\begin{array}{l}\text { Two neuroradiologists, both } \\
\text { blinded to tumor pathology. }\end{array}$ \\
\hline $\begin{array}{l}\text { Maynard J } \\
\text { et al.2020 [18] }\end{array}$ & 290 & $\begin{array}{c}40 \\
(33-52)\end{array}$ & $169 / 121$ & na & na & $0.44-0.62$ & $\begin{array}{l}\text { Three neuroradiologists, all } \\
\text { blinded to diagnosis. }\end{array}$ \\
\hline
\end{tabular}

$\perp$ Studies that included WHO Grade IV cases; na: not available, YOP: year of publication, $n$ : number, M/F: male/female, WHO: World Health Organization, ICC: intraclass correlation coefficient.
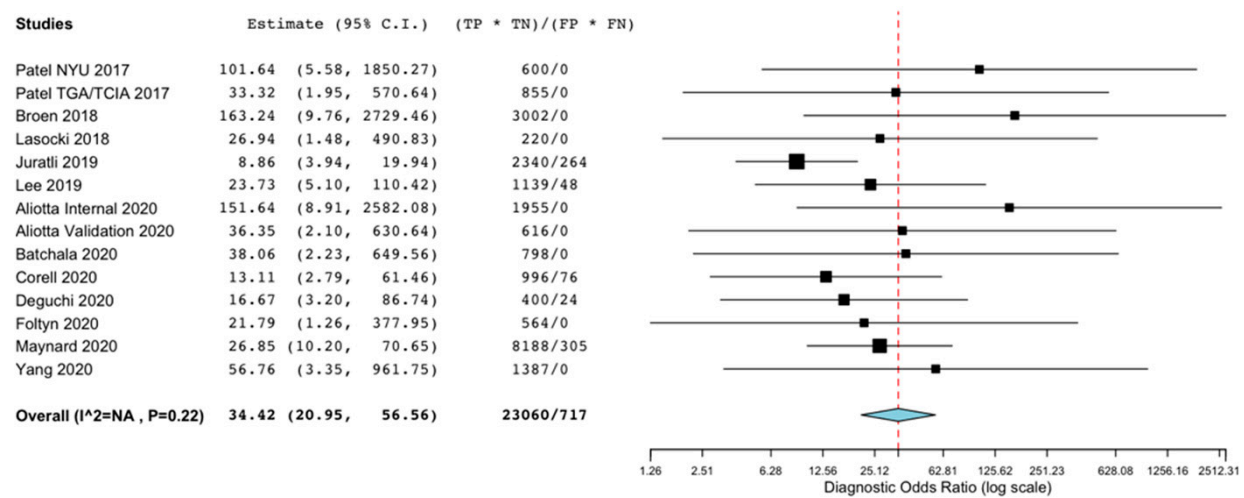

Figure 2. The forest plot presenting the effectiveness of the T2-FLAIR mismatch sign in diagnosing IDH mutant noncodeleted low grade gliomas. 


\subsection{Sensitivity and Specificity}

Due to high heterogeneity, the random effects model was applied to assess the sensitivity and specificity of the T2-FLAIR mismatch sign in diagnosing IDHmut-Noncodel LGGs. The pooled analysis yielded the following estimates (95\% CI; $p$-value; $I^{2}$ and Cochran's $Q$ indices for heterogeneity): a sensitivity of $40 \%\left(31-50 \% ; P_{z}=0.05 ; I^{2}=84.2, P_{Q}<0.01\right)$, and a specificity of $97 \%\left(93-99 \% ; P_{z}<0.01 ; I^{2}=82.6, P_{Q}<0.01\right)$. Results were statistically significant for both sensitivity and specificity. The forest plots for sensitivity and specificity are presented in Figure 3. The SROC curve is demonstrated in Figure 4.

A

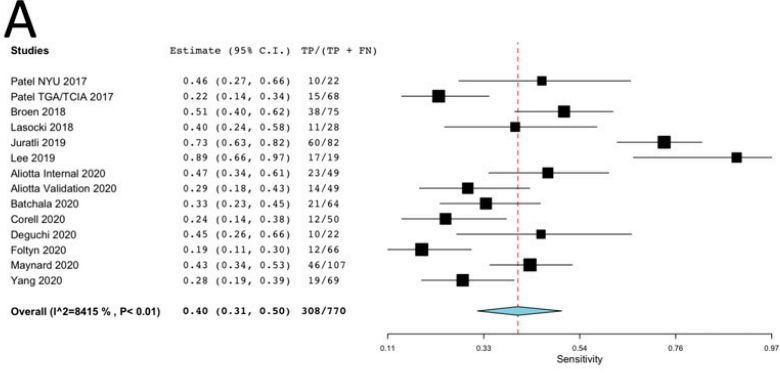

C

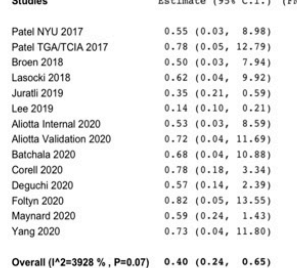

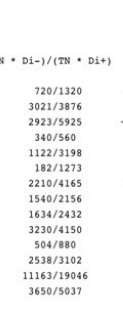

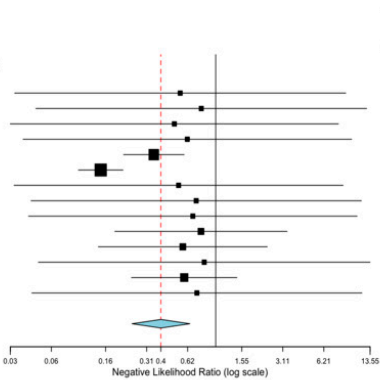

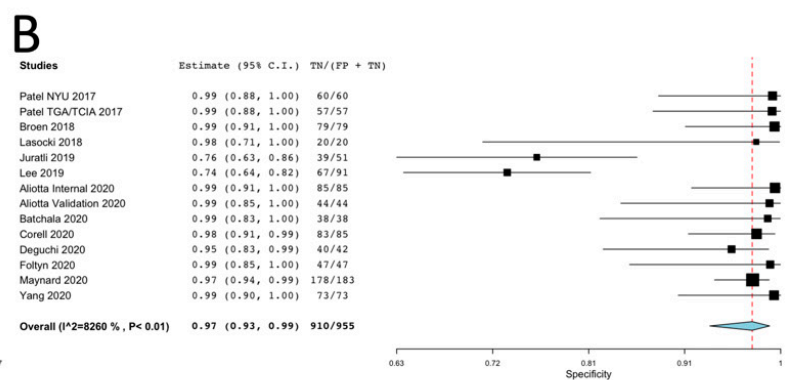

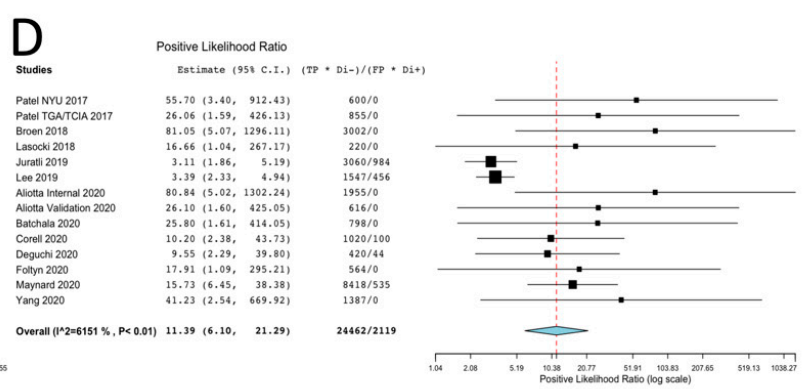

Figure 3. The forest plots presenting the (A) sensitivity, (B) specificity, (C) likelihood ratio for a negative test and (D) likelihood ratio for a positive test of the T2-FLAIR mismatch sign for the diagnosis of IDH mutant non-codeleted low grade gliomas.

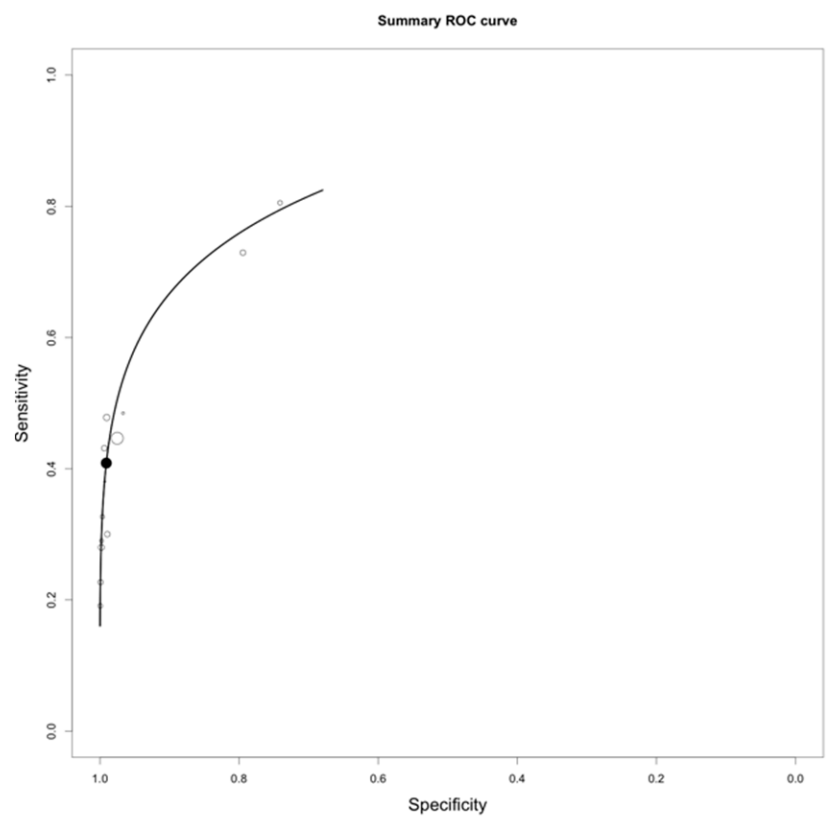

Figure 4. Summary receiver operating characteristic (SROC) curve of the T2-FLAIR mismatch sign's diagnostic accuracy in diagnosing IDH mutant non-codeleted lower grade gliomas. 


\subsection{Likelihood Ratios for Positive and Negative Results}

Due to high heterogeneity, the random effects model was used to assess the pooled $\mathrm{LR}+$ of the test. Statistical analysis resulted in a $\mathrm{LR}+$ of $11.39\left(6.10,21.29 ; P_{z}<0.01 ; I^{2}=61.5\right.$, $\left.P_{Q}<0.01\right)$.

Due to low heterogeneity, the fixed effects model was applied to assess the pooled LRof the test. Statistical analysis resulted in a statistically significant low $L R-[0.40(0.24,0.65$; $\left.\left.P_{z}<0.01 ; I^{2}=39.3, P_{Q}=0.07\right)\right]$.

The forest plots for pooled LR+ and LR- are shown in Figure 3.

\subsection{Risk of Bias Assessment}

We used the QUADAS-2 tool to identify possible risk of bias within the included studies. The assessment revealed low risk of bias and applicability concerns in all studies, except three $[9,10,13]$, where the risk was high in regard to the index test, due to the assessment of the MR images by a neurologist in one study and a neurosurgeon in two studies. A high applicability concern was found in one study regarding its index test, since there was no mentioning about the observers being blinded. The results are shown in detail in Table S2 (Supplementary Material).

\section{Discussion}

The T2-FLAIR mismatch sign has been previously reported as a highly specific imaging indicator of IDHmut-Noncodel LGGs. In their meta-analysis, Goyal [19] confirmed the association of T2-FLAIR mismatch sign with the disease, with high DOR, high specificity and low sensitivity [10]. Likewise, Park et al. [20] recently reported that the sign is a highly specific, though insensitive indicator of the disease. Accordingly, the present meta-analysis reports the high diagnostic accuracy of the mismatch sign to diagnose the disease [DOR (95\% CI): $34.42(20.95,56.56)]$. We also confirm its high specificity [97\% (93-99\%)] and low sensitivity $[40 \%(31-50 \%)]$ in diagnosing these groups of tumors.

The first to report the association of the sign with the diagnosis of the disease were Patel et al. [3]. The subject then attracted research attention from researchers who further studied the diagnostic accuracy of the biomarker. Lasocki et al. [8] also reported that $>50 \%$ T2-FLAIR mismatch is highly predictive of non-codeleted gliomas. Furthermore, Broen et al. [9] suggested that the mismatch sign is a highly specific imaging biomarker for IDH-mutant astrocytomas. Although Juratli et al. [10] reported that the mismatch sign is $76 \%$ specific in diagnosing the disease, they thereby reported that the T2-FLAIR mismatch sign performed $96 \%$ specificity in diagnosing non-codeleted gliomas in patients younger than 40 years old at diagnosis, with a tumor larger than $6 \mathrm{~cm}$ in diameter. However, the sensitivity for this subgroup was even lower than the overall sensitivity. The relatively low diagnostic accuracy presented by the study, might be due to not relying on the strict imaging criteria for the mismatch sign identification that Patel et al. first suggested [21]. In another study, apart from the diagnostic accuracy of the mismatch sign, Corell et al. [13] investigated its relation to methylation profiles. They confirmed its high specificity and low sensitivity, while methylation analysis indicated that the sign does not compromise a separate subentity. The high specificity was also confirmed in a recent study [18].

The diagnosis of gliomas, in general, is and will remain histopathological. Thus, surgery is necessary to remove the tissue and study its histopathological and molecular characteristics. The discovery of radiomic biomarkers may indicate the tumor's subtype preoperatively, or even judge the operative or non-operative nature of such a tumor. The mismatch sign is not consistently defined, since its definition varies throughout the included studies: a mismatch of $>50 \%,>75 \%$, or even an abstract definition of "complete or near/complete mismatch". This inconsistency often results in disagreement between observers, although the interobserver agreement in all the included studies was moderate to high (Table 1).

The T2/FLAIR mismatch sign is reported as a highly specific biomarker, though its low sensitivity in diagnosing IDHmut-Noncodel LGGs led scientists towards combining 
additional parameters to improve its diagnostic performance. Batchala et al. [11] studied two retrospective cohorts, of which only the one was eligible for inclusion to the quantitative analysis of the present study. Apart from validating the high specificity of the test, they also suggested a 2-step classification algorithm based on the T2-FLAIR mismatch sign and a multivariate logistic regression model involving multiple parameters. This approach demonstrates an overall moderate prediction accuracy for $1 \mathrm{p} / 19 \mathrm{q}$-codeletion status in IDH-mutant LGGs [11]. Lee et al. [12] reported a specificity of $73.6 \%$ and sensitivity of $89.5 \%$, the highest estimate for sensitivity among the included studies. They also suggested that combining the apparent diffusion coefficient (ADC) and cerebral blood volume (CBV) histogram parameters with the presence of the mismatch sign may improve the diagnostic accuracy of non-codeleted LGGs [12]. Additionally, Yang et al. [17] investigated a model for predicting the codeletion status of LGGs. They concluded that a combination of the mismatch sign, relative ADC, intratumoral susceptibility signals, and maximum relative CBV may improve the accuracy for predicting the $1 \mathrm{p} / 19 \mathrm{q}$ codeletion status among LGGs in clinical practice.

As research interest about the mismatch sign increased, studies investigating the pathology and microenvironment of these tumors emerged. Deguchi et al. [14] reported a statistically significant association of the mismatch sign with the formation of microcysts in IDHmut-Noncodel LGGs. They further concluded that it might be common in a distinct subgroup of astrocytomas, known as protoplasmic astrocytomas. Foltyn et al. [15] reported higher $\mathrm{ADC}$ and lower $\mathrm{rCBV}$ values between gliomas with or without the presence of the mismatch sign. They also suggested potential differences in the cellularity and microenvironment within LGGs, since they present lower ADC values in the FLAIR-hyperintense rim and higher values in the hypointense interior on diffusion weighted imaging (DWI).

The high ADC values in IDH-mutant LGGs may explain the finding of microcysts reported in a previous study [14]. Aliotta et al. [16] intended to develop an ADC analysisbased approach to consistently and objectively identify IDHmut-Noncodel LGGs. Moreover, the combination of volumetric ADC and the presence of the mismatch sign for diagnosing IDHmut-Noncodel LGGs, resulted in improved sensitivity and the same specificity compared to the mismatch sign alone [16].

It is of high importance to mention that the T2/FLAIR mismatch sign may be found in other molecular subtypes, including IDH-mutant 1p/19q codeleted and IDH-wildtype gliomas. A recent case series reported five cases of false-positive mismatch signs in patients with gliomas other than $1 \mathrm{p} / 19 \mathrm{q}$ non-codeleted LGGs [22]. Only one out of the five cases were adult, possibly indicating that age is an important factor with regard to the clinical application of the mismatch sign. The sign might be associated with tumor subtypes other than IDHmut-Noncodel LGGs in the pediatric population, thus, it might be interpreted and used cautiously in this specific subgroup [21]. Additionally, the sign is reported to be identified in dysembryoplastic neuroepithelial tumors [23], hence it is not entirely specific for IDHmut-Noncodel LGGs and should not be used as a stand-alone diagnostic imaging biomarker. Nevertheless, the sign is reported as absent in WHO Grade IV glioblastomas [15]. A recent article aiming to determine imaging metrics predictive of the IDH mutation in glioblastomas, reported fluid attenuation in non-contrast-enhancing tumors as a novel imaging biomarker, along with other conventional MRI metrics and patient age [24].

The present study is characterized by several limitations that should be mentioned. The exclusion of grey literature in our data acquisition strategy suggests possible publication bias. Thus, the results of the present analysis should be interpreted cautiously since results may be overestimated in meta-analyses including published data only [25]. Additionally, some of the included studies lacked certain information that would have allowed for testing the diagnostic performance of the mismatch sign by subgroups (age, sex, WHO grade, etc.) Furthermore, our review included retrospective studies only, with a limited number of subjects. Lastly, our study is subject to language bias since only studies written in English were included. 


\section{Conclusions}

The T2-FLAIR mismatch sign is a highly specific biomarker for the diagnosis of IDH-mutant non-codeleted LGGs. However, the test has been occasionally found positive in few other tumor types, thus it has to be interpreted with caution, especially in the pediatric population. The test also reveals a high number of false negative results. The diagnostic accuracy of the mismatch sign might be improved if the imaging criteria are strictly applied or the sign is combined with further imaging parameters. Further research is needed to investigate the mismatch sign's accuracy and its relationship with other imaging biomarkers in predicting IDH-mutant non-codeleted LGGs.

Supplementary Materials: The following are available online at https:/ /www.mdpi.com/article/10 .3390/diagnostics11091620/s1, Table S1: Table presenting the PRISMA-DTA checklist of the study, Table S2: Table presenting the results of the QUADAS-2 tool assessment.

Author Contributions: Conceptualization, A.A. and P.P.; methodology, A.A. and E.T.B.; formal analysis, A.A.; data curation, E.T.B.; writing-original draft preparation, A.A.; writing-review and editing, A.A., E.T.B. and P.P.; visualization, A.A.; supervision, P.P.; project administration, A.A. and P.P. All authors have read and agreed to the published version of the manuscript.

Funding: This research received no external funding.

Institutional Review Board Statement: Not applicable.

Informed Consent Statement: Not applicable.

Conflicts of Interest: The authors declare no conflict of interest.

\section{References}

1. Louis, D.N.; Perry, A.; Reifenberger, G.; von Deimling, A.; Figarella-Branger, D.; Cavenee, W.K.; Ohgaki, H.; Wiestler, O.D.; Kleihues, P.; Ellison, D.W. The 2016 World Health Organization Classification of Tumors of the Central Nervous System: A Summary. Acta Neuropathol. 2016, 131, 803-820. [CrossRef] [PubMed]

2. van Timmeren, J.E.; Cester, D.; Tanadini-Lang, S.; Alkadhi, H.; Baessler, B. Radiomics in Medical Imaging-“How-to” Guide and Critical Reflection. Insights Imaging 2020, 11, 1-16. [CrossRef] [PubMed]

3. Patel, S.H.; Poisson, L.M.; Brat, D.J.; Zhou, Y.; Cooper, L.; Snuderl, M.; Thomas, C.; Franceschi, A.M.; Griffith, B.; Flanders, A.E.; et al. T2-FLAIR Mismatch, an Imaging Biomarker for IDH and 1p/19q Status in Lower-Grade Gliomas: A TCGA/TCIA Project. Clin. Cancer Res. 2017, 23, 6078-6085. [CrossRef]

4. Rutter, C.M.; Gatsonis, C.A. A Hierarchical Regression Approach to Meta-Analysis of Diagnostic Test Accuracy Evaluations. Stat. Med. 2001, 20, 2865-2884. [CrossRef]

5. Wallace, B.C.; Dahabreh, I.J.; Trikalinos, T.A.; Lau, J.; Trow, P.; Schmid, C.H. Closing the Gap between Methodologists and End-Users: R as a Computational Back-End. J. Stat. Softw. 2012, 49, 1-15. [CrossRef]

6. McInnes, M.D.F.; Moher, D.; Thombs, B.D.; McGrath, T.A.; Bossuyt, P.M.; the PRISMA-DTA Group; Clifford, T.; Cohen, J.F.; Deeks, J.J.; Gatsonis, C.; et al. Preferred Reporting Items for a Systematic Review and Meta-Analysis of Diagnostic Test Accuracy Studies: The PRISMA-DTA Statement. JAMA 2018, 319, 388. [CrossRef]

7. Whiting, P.F.; Rutjes, A.W.S.; Westwood, M.E.; Mallett, S.; Deeks, J.J.; Reitsma, J.B.; Leeflang, M.M.G.; Sterne, J.A.C.; Bossuyt, P.M.M.; QUADAS-2 Group. QUADAS-2: A Revised Tool for the Quality Assessment of Diagnostic Accuracy Studies. Ann. Intern. Med. 2011, 155, 529-536. [CrossRef]

8. Lasocki, A.; Gaillard, F.; Gorelik, A.; Gonzales, M. MRI Features Can Predict 1p/19q Status in Intracranial Gliomas. AJNR Am. J. Neuroradiol. 2018, 39, 687-692. [CrossRef]

9. Broen, M.P.G.; Smits, M.; Wijnenga, M.M.J.; Dubbink, H.J.; Anten, M.H.M.E.; Schijns, O.E.M.G.; Beckervordersandforth, J.; Postma, A.A.; van den Bent, M.J. The T2-FLAIR Mismatch Sign as an Imaging Marker for Non-Enhancing IDH-Mutant, 1p/19q-Intact Lower-Grade Glioma: A Validation Study. Neuro Oncol. 2018, 20, 1393-1399. [CrossRef]

10. Juratli, T.A.; Tummala, S.S.; Riedl, A.; Daubner, D.; Hennig, S.; Penson, T.; Zolal, A.; Thiede, C.; Schackert, G.; Krex, D.; et al. Radiographic Assessment of Contrast Enhancement and T2/FLAIR Mismatch Sign in Lower Grade Gliomas: Correlation with Molecular Groups. J. Neurooncol. 2019, 141, 327-335. [CrossRef] [PubMed]

11. Batchala, P.P.; Muttikkal, T.J.E.; Donahue, J.H.; Patrie, J.T.; Schiff, D.; Fadul, C.E.; Mrachek, E.K.; Lopes, M.-B.; Jain, R.; Patel, S.H. Neuroimaging-Based Classification Algorithm for Predicting 1p/19q-Codeletion Status in IDH-Mutant Lower Grade Gliomas. Am. J. Neuroradiol. 2019, 40, 426-432. [CrossRef] [PubMed]

12. Lee, M.K.; Park, J.E.; Jo, Y.; Park, S.Y.; Kim, S.J.; Kim, H.S. Advanced Imaging Parameters Improve the Prediction of Diffuse Lower-Grade Gliomas Subtype, IDH Mutant with No 1p19q Codeletion: Added Value to the T2/FLAIR Mismatch Sign. Eur. Radiol. 2020, 30, 844-854. [CrossRef] [PubMed] 
13. Corell, A.; Ferreyra Vega, S.; Hoefling, N.; Carstam, L.; Smits, A.; Olsson Bontell, T.; Björkman-Burtscher, I.M.; Carén, H.; Jakola, A.S. The Clinical Significance of the T2-FLAIR Mismatch Sign in Grade II and III Gliomas: A Population-Based Study. BMC Cancer 2020, 20, 450. [CrossRef] [PubMed]

14. Deguchi, S.; Oishi, T.; Mitsuya, K.; Kakuda, Y.; Endo, M.; Sugino, T.; Hayashi, N. Clinicopathological Analysis of T2-FLAIR Mismatch Sign in Lower-Grade Gliomas. Sci. Rep. 2020, 10, 10113. [CrossRef]

15. Foltyn, M.; Nieto Taborda, K.N.; Neuberger, U.; Brugnara, G.; Reinhardt, A.; Stichel, D.; Heiland, S.; Herold-Mende, C.; Unterberg, A.; Debus, J.; et al. T2/FLAIR-Mismatch Sign for Noninvasive Detection of IDH-Mutant 1p/19q Non-Codeleted Gliomas: Validity and Pathophysiology. Neurooncol. Adv. 2020, 2, vdaa004. [CrossRef]

16. Aliotta, E.; Dutta, S.W.; Feng, X.; Tustison, N.J.; Batchala, P.P.; Schiff, D.; Lopes, M.B.; Jain, R.; Druzgal, T.J.; Mukherjee, S.; et al. Automated Apparent Diffusion Coefficient Analysis for Genotype Prediction in Lower Grade Glioma: Association with the T2-FLAIR Mismatch Sign. J. Neurooncol. 2020, 149, 325-335. [CrossRef]

17. Yang, X.; Lin, Y.; Xing, Z.; She, D.; Su, Y.; Cao, D. Predicting 1p/19q Codeletion Status Using Diffusion-, Susceptibility-, Perfusion-Weighted, and Conventional MRI in IDH-Mutant Lower-Grade Gliomas. Acta Radiol. 2020. [CrossRef]

18. Maynard, J.; Okuchi, S.; Wastling, S.; Busaidi, A.A.; Almossawi, O.; Mbatha, W.; Brandner, S.; Jaunmuktane, Z.; Koc, A.M.; Mancini, L.; et al. World Health Organization Grade II/III Glioma Molecular Status: Prediction by MRI Morphologic Features and Apparent Diffusion Coefficient. Radiology 2020, 296, 111-121. [CrossRef]

19. Goyal, A.; Yolcu, Y.U.; Goyal, A.; Kerezoudis, P.; Brown, D.A.; Graffeo, C.S.; Goncalves, S.; Burns, T.C.; Parney, I.F. The T2-FLAIRMismatch Sign as an Imaging Biomarker for IDH and 1p/19q Status in Diffuse Low-Grade Gliomas: A Systematic Review with a Bayesian Approach to Evaluation of Diagnostic Test Performance. Neurosurg. Focus 2019, 47, E13. [CrossRef]

20. Park, S.I.; Suh, C.H.; Guenette, J.P.; Huang, R.Y.; Kim, H.S. The T2-FLAIR Mismatch Sign as a Predictor of IDH-Mutant, 1p/19q-Noncodeleted Lower-Grade Gliomas: A Systematic Review and Diagnostic Meta-Analysis. Eur. Radiol. 2021. [CrossRef]

21. Jain, R.; Johnson, D.R.; Patel, S.H.; Castillo, M.; Smits, M.; van den Bent, M.J.; Chi, A.S.; Cahill, D.P. "Real World" Use of a Highly Reliable Imaging Sign: “T2-FLAIR Mismatch" for Identification of IDH Mutant Astrocytomas. Neuro Oncol. 2020, 22, 936-943. [CrossRef]

22. Johnson, D.R.; Kaufmann, T.J.; Patel, S.H.; Chi, A.S.; Snuderl, M.; Jain, R. There Is an Exception to Every Rule-T2-FLAIR Mismatch Sign in Gliomas. Neuroradiology 2019, 61, 225-227. [CrossRef] [PubMed]

23. Onishi, S.; Amatya, V.J.; Kolakshyapati, M.; Takano, M.; Yonezawa, U.; Taguchi, A.; Kaichi, Y.; Takeshima, Y.; Awai, K.; Sugiyama, K.; et al. T2-FLAIR Mismatch Sign in Dysembryoplasticneuroepithelial Tumor. Eur.J. Radiol. 2020, $126,108924$. [CrossRef] [PubMed]

24. Patel, S.H.; Batchala, P.P.; Muttikkal, T.J.E.; Ferrante, S.S.; Patrie, J.T.; Fadul, C.E.; Schiff, D.; Lopes, M.B.; Jain, R. Fluid Attenuation in Non-contrast-enhancing Tumor (NCET): An MRI Marker for Isocitrate Dehydrogenase (IDH) Mutation in Glioblastoma. J. Neurooncol. 2021, 152, 523-531. [CrossRef] [PubMed]

25. Hopewell, S.; McDonald, S.; Clarke, M.; Egger, M. Grey Literature in Meta-Analyses of Randomized Trials of Health Care Interventions. Cochrane Database Syst. Rev. 2007, MR000010. [CrossRef] 